\title{
The combined impact of diet, physical activity, sleep and screen time on academic achievement: a prospective study of elementary school students in Nova Scotia, Canada
}

\author{
Erin L. Faught', John P. Ekwaru', Douglas Gleddie², Kate E. Storey', Mark Asbridge ${ }^{3}$ and Paul J. Veugelers ${ }^{1 *}$
}

\begin{abstract}
Background: Few studies have investigated the independent associations of lifestyle behaviors (diet, physical activity, sleep, and screen time) and body weight status with academic achievement. Even fewer have investigated the combined effect of these behaviors on academic achievement. We hypothesize that the combined effect of these behaviors will have a higher impact on academic achievement than any behavior alone, or that of body weight status.

Methods: In 2011, 4253 grade 5 (10-11 years old) students and their parents were surveyed about the child's diet, physical activity, screen time and sleep. Students' heights and weights were measured by research assistants. Academic achievement was measured using provincial standardized exams in mathematics, reading and writing, and was expressed as 'meeting' or 'not meeting' expectations as per standardized criterion. Exams were written 1 year following the measurement of lifestyle behaviors. Lifestyle behaviors were measured with self- and parental proxy reports and expressed as meeting recommendations (yes/no) for each behavior. Mixed effects logistic regression models adjusting for demographic confounders and caloric intake were used to determine the independent and combined associations.

Results: Meeting dietary recommendations was associated with increased likelihood of meeting academic expectations for each of math, reading and writing. Meeting recommendations for screen time and sleep was associated with meeting expectations for writing. For all three subjects, meeting additional lifestyle behavior recommendations was associated with higher likelihood of meeting expectations. Children who met 7-9 lifestyle behavior recommendations had greater than three-times the odds of meeting expectations for reading compared to those who met 0-3 recommendations (OR: $3.07,95 \% \mathrm{Cl}: 2.09,4.51$ ), and 1.47 and 2.77 times the odds of meeting expectations in mathematics and writing, respectively. Body weight status was not associated with academic achievement.

Conclusions: We found that lifestyle behaviors, not body weight status, are strongly associated with student academic performance. Promoting compliance with established healthy lifestyle recommendations could improve both the health and educational outcomes of school-aged children. School-based health promotion initiatives that target multiple lifestyle behaviors may have a greater effect on academic achievement than those that focus on a single behavior.
\end{abstract}

Keywords: Diet, Physical activity, Sedentary behavior, Sleep, Children, School health, Epidemiology, Childhood obesity

* Correspondence: paul.veugelers@ualberta.ca

${ }^{1}$ Population Health Intervention Research Unit, School of Public Health,

University of Alberta, 3-50 University Terrace, 8303-112 street, Edmonton, AB

T6G 2T4, Canada

Full list of author information is available at the end of the article

(c) The Author(s). 2017 Open Access This article is distributed under the terms of the Creative Commons Attribution 4.0 International License (http://creativecommons.org/licenses/by/4.0/, which permits unrestricted use, distribution, and reproduction in any medium, provided you give appropriate credit to the original author(s) and the source, provide a link to the Creative Commons license, and indicate if changes were made. The Creative Commons Public Domain Dedication waiver (http://creativecommons.org/publicdomain/zero/1.0/) applies to the data made available in this article, unless otherwise stated. 


\section{Background}

It is established that academic success in childhood and adolescence is a strong predictor of future wealth, productivity and health $[1,2]$. Provided this, attention to children's academic achievement must be taken into consideration by public health decision makers aiming to prevent chronic diseases and improve health across the lifespan. This includes not only the resources devoted to educational attainment, but an understanding of the indirect lifestyle factors the help to shape childhood and adolescent academic success.

Healthy diets, sufficient physical activity and sleep, and minimal screen time contribute to a healthy lifestyle, are important to children's cognitive performance during development, and may potentially optimize academic success [3-11]. Findings from studies investigating the relationship between individual lifestyle behaviors and academic achievement have demonstrated that children with healthy lifestyle behaviors perform better academically [10, 12-15]. In particular, reductions in children's time spent in physical education has motivated substantial study of the relationship between physical activity and academic achievement [16]. However, few studies have investigated the independent association of multiple lifestyle behaviors with academic achievement; particular the potential confounding in the observed relationship given the strong correlation between lifestyle factors [17-20]. For example, levels of sleep are associated with academic achievement, yet screen time has been shown to be associated with both sleep and academic achievement [14, 21, 22]. If screen time is not taken into consideration when evaluating the association between sleep and academic achievement, the observed relationship may, in part, have contributed to the effects of screen time.

Some scholars have hypothesized that healthy lifestyle behaviors do not act in isolation in their relationship with academic achievement, and that the effects of exhibiting multiple healthy lifestyle behaviors may be greater than the sum of their individual effects [17, 23, 24]. To our knowledge, only two studies have investigated this hypothesis, and both have found convincing evidence in support of it $[17,25]$. Using self-reported health data in a cohort of Spanish adolescents, Martinez-Gomez et al. (2014) found that meeting recommendations for 3-4 lifestyle behaviors was associated with higher odds achieving passing grades in Language and Literature and Math, in girls only, compared to those that met fewer recommendations [17]. In a sample of American children in a low-income urban distract, Ickovics et al. found that children exhibiting the largest number of healthy lifestyle behaviors, including a healthy body weight, were more than twice as likely to meet goal on standardized exams compared to those with the fewest
[25]. Further investigation of this hypothesis is merited to inform effective health promotion in children, particularly school-based initiatives. Many health promotion initiatives based in schools have focused on singular components of a healthy lifestyle; addressing multiple behaviors simultaneously may produce cumulative benefits that impact both health and academic outcomes.

Our aim is to investigate the independent and combined effects of lifestyle behaviors, as well as body weight status, on children's academic achievement on standardized exams using a large, population-based sample of grade 5 students from Nova Scotia, Canada. We aim to complement and expand on previous work by using a large, population-based sample as well as including a wide range of dietary components, sleep duration and adherence to established recommendations for sleep, objectively measured heights and weights, and standardized exam results in addition to measures of physical activity and screen time. We evaluate children's lifestyle behaviors by their adherence to established health recommendations from Health Canada, the United States Departments of Health and Human Services and Agriculture, and the World Health Organization (WHO) for each behavior in order to improve interpretability and applicability of results for public health decision makers [26-28]. We hypothesize that each lifestyle behavior of interest (diet, physical activity, screen time and sleep) will have an independent effect on academic achievement. We also hypothesize that the combined effect of multiple healthy lifestyle behaviors will have a greater effect on academic achievement than their respective individual effects.

\section{Methods}

The 2011 Children's Lifestyle And School performance Study (CLASS) is a population-based survey examining lifestyle behaviors, weight status, and academic achievement of grade 5 (mostly 10-11 years old) students in Nova Scotia, Canada. All grade 5 students in Nova Scotia, their parents or guardians, and school administrators were invited to participate in the study. Of all schools that had grade 5 classes in the province, principals in 269 of 286 (94.1\%) schools provided consent for participation. Following consent from the principal, home packages, including consent forms, were sent home to all parents and guardians of grade 5 children in the school. Parental consent to participate in the survey was provided for 6591 students out of 8736 that were distributed, resulting in an average response rate of $75.4 \%$ per school. Of these, 1169 (17.7\%) were absent the day of the survey, did not complete the survey, or had caloric intakes $<500$ or $>5000 \mathrm{kcal}$ as these values are considered unrealistic [29], and as such were excluded from analysis, leaving 5422 eligible students. Of remaining students, 4253 (78\%) could be 
successfully linked with their achievement on grade 6 standardized exams in Reading, Writing and Mathematics that were written one full year following the lifestyle behavior assessment; the resulting overall completion rate was $64.5 \%$. Further information and the survey used can be found at http://www.nsclass.ca.

\section{Data collection}

Trained research assistants travelled to participating schools to administer surveys during classroom time. Students completed two surveys. The student survey contained questions about habitual physical activity and personal perceptions about diet. Students also completed the Harvard Food Frequency Questionnaire for Youth/ Adolescents (YAQ), a 147-item validated questionnaire adapted for Canadian use that measures habitual intake over the past 12 months [30]. Research assistants measured students' heights to the nearest $0.1 \mathrm{~cm}$ and weights to the nearest $0.1 \mathrm{~g}$ using calibrated stadiometers and scales as per standard protocol [31]. Parents completed a home survey reporting on children's sleep habits and screen time usage, as well questions on household income and parental level of education.

\section{Exposures}

\section{Diet}

We employed the Harvard Food Frequency Questionnaire YAQ to evaluate students dietary consumption. The YAQ contains 147 questions, 135 of which are regarding specific food items and 11 of which relate to food habits (eating in front of the TV, etc.), about the frequency of consuming items over the past year [30]. Nutrient information was derived using the Canadian Nutrient File (CNF) [32], a Canadian nutrient composition database for commonly consumed foods in Canada. Students' consumption was evaluated with respect to meeting age-specific recommendations from Health Canada's Eating Well with Canada's Food Guide [26]. This includes recommendations for daily servings of vegetables and fruit (6 servings), grain products (6 servings), milk and alternatives (3-4 servings) and meat and alternatives ( 2 servings). The Canadian Food Guide does not have specific recommendations for saturated fat and free sugar intake. Instead we used recommendations developed for American youth for saturated fat intake $(<10 \%$ of total energy intake) [28], and for free sugars consumption - representing sugars that are added during food processing, not naturally occurring sugars such as lactose - we followed 2015 World Health Organization recommendations $(<10 \%$ of total energy intake) [27]. We calculated energy intake using responses from the YAQ.

\section{Physical activity}

The student survey contained the Physical Activity Questionnaire for Children (PAQ-C) instrument, a selfadministered, 10-item physical activity recall instrument [33]. The questionnaire has been validated to measure general levels of moderate-to-vigorous physical activity in children aged 8-14 [33-35]. A score between 0 and 5 was calculated from responses for each student, with higher scores indicating higher levels of physical activity. Cutoff values indicating 'healthy fit' or 'at-risk' in regards to cardio-respiratory fitness for the PAQ-C have been established for children: 2.7 for girls and 2.9 for boys [36]. As such, meeting recommendations for physical activity that correspond with healthy cardio-respiratory fitness were assessed using these cutoff values.

\section{Screen time}

Parents were asked: On average, about how many hours per day does your Grade 5 child spend watching TV not including school hours? Possible responses were: Less than $1 \mathrm{~h}$ a day, $1-2 \mathrm{~h}$ per day, 3-4 h per day, or 5 or more hours per day. Children were described as meeting sedentary behavior recommendations if total screen time from television watching was less than $2 \mathrm{~h}$ per day as per the Canadian Sedentary Behavior Guidelines [37].

\section{Sleep}

Parents reported habitual wake up and bed times for children on usual weekdays and weekends. Parents were asked: At what time does your child usually wake up during a) the week (Monday to Friday) and b) the weekend (Saturday and Sunday)? Possible responses were before 6:30 am, 6:30-7:00 am, 7:00-7:30 am, 7:30-8:00 am, 8:00-8:30 am, 8:30-9:00 am and after 9:00 am. Parents were also asked: At what time does your child usually go to bed during a) the week (Sunday to Thursday) and b) the weekend (Friday and Saturday)? Possible responses were before 8:00 pm, 8:00-8:30 pm, 8:30-9:00 pm, 9:009:30 pm, 9:30-10:00 pm, 10:00-10:30 pm, and after 10:30 pm. Finally, sleep duration was calculated based on usual bed and wake up times with usual time to fall asleep subtracted for each of weekday and weekend days. Average nightly sleep duration for a typical week was calculated from the mean sleep duration of five weekdays and two weekend days. Students were described as meeting sleep duration recommendations if average duration was between 9 and $11 \mathrm{~h}$, as recommended by the National Sleep Foundation [38].

\section{Body weight status}

Children's body mass index (BMI) was calculated using measured heights and weights. Body weight status was assessed using the International Obesity Task Force 
(IOTF) age- and gender-specific BMI cutoffs for overweight and obesity [39].

\section{Potential confounders}

Analyses were adjusted for child's gender, parental education, and household income as assessed by categorical questions in the parental home survey as well as region of residence (urban or rural) determined by postal code. Energy intake was included in analyses that included YAQ data as is recommended [29].

\section{Outcome}

\section{Academic achievement}

The Nova Scotia Department of Early Education and Childhood Development provided results for standardized provincial exams written by participants in grade 6 (spring 2012), 1 year following the measurement of other variables (spring 2011), in the subjects of Mathematics, Reading, and Writing. Results were provided as dichotomous values of 'meeting expectations' and 'not meeting expectations'. The Nova Scotia Department of Early Education and Childhood Development, who administers the exams, provides standardized rubrics for the exams to determine of children are meeting and not meeting expectations. Teachers from across the province are invited to assist in the marking of assessments. Further information about this process can be found at https://plans.ednet.ns.ca/about-plans.

\section{Analysis}

All analyses were weighted for non-response to represent provincial estimates of the grade 5 student population of Nova Scotia. Response weights were calculated based on postal-code level estimates of household data, available from Canadian census data for both participants and non-participants [40]. As response rates were lower among the lowest income deciles, weights were applied to overcome non-response bias from lowerincome neighbourhoods in Nova Scotia [40]. We applied mixed effects models due to the clustering of students within schools. Correlations between exposures of interest were evaluated and can be found in the supplementary material (Additional file 1). Univariable logistic regression was first used to assess the associations between each individual student's lifestyle behaviors, dichotomized into meeting and not meeting recommendations for each, and their academic achievement. Next, we used multivariable models (Model 1) to adjust for potential confounders and body weight status. Models for individual exposures of interest were run including potential confounders (nine separate models for each recommendation). Another model was run with confounders only, producing the results for Model 1 in Tables 2, 3, and 4 for confounders. Finally, we considered all lifestyle behaviors simultaneously in a full model (model 2) to assess independent associations between meeting each lifestyle behavior recommendation, body weight status, and academic achievement.

To assess combined effects of meeting each lifestyle behavior recommendation, we also considered the effect of the number of recommendations met up to 9 (vegetables and fruit, grain products, milk and alternatives, meat and alternatives, saturated fat, free sugars, physical activity, sleep, and screen time). As with assessing independent associations, univariable and multivariable regression models were employed treating the score as both categorical and continuous to assess the cumulative impact of meeting lifestyle behavior recommendations and academic achievement. This analysis was conducted treating the score as a continuous variable and by splitting scores into three categories, low (meeting 1-3 recommendations), medium (meeting 4-6 recommendations) and high (meeting 7-9 recommendations). All analyses were conducted using Stata version 14.1 IC (StataCorp, Texas, USA).

\section{Results}

Table 1 shows that $87.4 \%$ of students met expectations for reading, $89.1 \%$ met expectations for writing, and $70.6 \%$ met expectations for mathematics. The percentage of children meeting selected lifestyle behavior recommendations was: $32.2 \%$ for Vegetables and Fruits, 20.8\% for Grain Products, 56.0 for Milk and Alternatives, 86.4 for Meat and Alternatives, $54.3 \%$ for saturated fat intake, $62.6 \%$ for free sugars intake, $76.7 \%$ for physical activity as per the PAQ-C, $91.1 \%$ for sleep duration, and $77.8 \%$ for screen time. Meeting recommendations for milk and alternatives, meat and alternatives, free sugars, sleep, and screen time all had significant univariate associations with meeting expectations for mathematics (Table 2, Model 1), while vegetables and fruit, grain products, milk and alternatives, meat and alternatives, saturated fat, and free sugars all had significant univariate associations with meeting expectations for reading (Table 3, Model 1). Meeting recommendations for vegetables and fruit, meat and alternatives, free sugars, physical activity, sleep and screen time all had significant univariate associations with meeting expectations for writing. Parental level of education, household income, and gender were all significantly associated with the likelihood of meeting expectations for each subject, while obesity only had a significant univariate association with meeting expectations in mathematics.

After adjusting for potential confounders, meeting recommendations for milk and alternatives, meat and alternatives, and free sugars continued to have significant positive associations with meeting recommendations for mathematics (Table 2, Model 1). Where meeting 
Table 1 Sample characteristics of grade 5 students participating in the CLASS II Project in Nova Scotia, Canada

\begin{tabular}{|c|c|}
\hline Characteristics & $n=4253$ \\
\hline Age, mean (SD), years & $11.0(0.4)$ \\
\hline Proportion Male (sex), \% & 47.2 \\
\hline Overweight or obese, \% & 34.7 \\
\hline Energy Intake, mean (SD), kcal & $1849.9(808.1)$ \\
\hline $\begin{array}{l}\text { Percentage of children who are meeting } \\
\text { lifestyle behavior recommendations, } \%\end{array}$ & $\%$ \\
\hline Vegetables and Fruits (6 servings) & 32.2 \\
\hline Grain Products (6 servings) & 20.8 \\
\hline Milk and Alternatives (3-4 servings) & 56.0 \\
\hline Meat and Alternatives (1-2 servings) & 86.4 \\
\hline Saturated Fat Intake ( $<10 \%$ total energy) & 54.3 \\
\hline Free Sugars ( $<10 \%$ total energy) & 62.6 \\
\hline $\begin{array}{l}\text { Physical Activity (PAQ-C Score }>=2.7 \text { for girls, } \\
>=2.9 \text { for boys) }\end{array}$ & 76.7 \\
\hline Sleep Duration (9-11 h) & 91.1 \\
\hline Screen Time ( $<=2 \mathrm{~h}$ day of television) & 77.8 \\
\hline $\begin{array}{l}\text { Percentage of children meeting multiple } \\
\text { lifestyle behavior recommendations, \% }\end{array}$ & $\%$ \\
\hline Low (1-3) & 7.9 \\
\hline Medium (4-6) & 64.7 \\
\hline High (7-9) & 27.5 \\
\hline Academic Achievement, \% meeting expectations & $\%$ \\
\hline Reading & 87.4 \\
\hline Writing & 89.1 \\
\hline Mathematics & 70.6 \\
\hline Parental Education, \% & $\%$ \\
\hline Secondary or Less & 17.3 \\
\hline College Diploma & 38.4 \\
\hline University or Graduate degree & 36.3 \\
\hline Missing/Prefer not to answer & 8.0 \\
\hline Household Income (CAN\$), \% & $\%$ \\
\hline$<=20,000$ & 20.3 \\
\hline $20,001-40,000$ & 13.3 \\
\hline $40,001-60,000$ & 24.1 \\
\hline$>=60,001$ & 19.8 \\
\hline Missing/Prefer not to answer & 22.5 \\
\hline Region of Residence, \% & $\%$ \\
\hline Urban & 69.7 \\
\hline Rural & 30.3 \\
\hline
\end{tabular}

expectations for reading was the outcome, meeting recommendations for vegetables and fruit, grain products, milk and alternatives, meat and alternatives, saturated fat and free sugars were all associated with increased likelihood of meeting expectations (Table 3, Model 1).
Finally, meeting recommendations for meat and alternatives, free sugars, sleep, and screen time were all associated with increased likelihood of meeting expectations for writing (Table 4, Model 1). Body weight status did not have an association with any outcome in these models.

When considering all lifestyle behaviors simultaneously, only meeting recommendations for milk and alternatives, and meat and alternatives remained significantly associated with meeting expectations for mathematics; meeting recommendations for free sugars was borderline significant (Table 2, Model 2: OR: 1.20 [95\% CI: 0.99, 1.45]). Meeting expectations for grain products, milk and alternatives, meat and alternatives, saturated fat and free sugars were all positively associated with meeting expectations for reading (Table 3, Model 2). Meeting recommendations for meat and alternatives, free sugars, sleep, and screen time had significant, positive associations with meeting expectations for writing (Table 4, Model 2). Neither overweight nor obesity demonstrated any association with meeting expectations for any subject.

Considering the combined effect of the nine criteria, for each additional criterion met, the odds of meeting the expectations for mathematics was 1.13 times higher (OR: 1.13 [95\% CI: 1.06, 1.20]). Table 5 shows that each additional criterion met also increased odds of meeting recommendations for reading by 1.26 times, (OR: 1.26 [95\% CI: 1.17, 1.35]), and by 1.21 times for meeting recommendations in writing (OR: 1.21 [95\% CI: 1.11, 1.32]).

The criteria were also considered in groups representing low, medium, and high compliance. Respectively, 7.9, 64.6, and $27.4 \%$ were in the low, medium and high categories. Compared to the lowest category, children who were in the highest category had 1.47 times the odds of meeting expectations for mathematics (Table 5: OR: 1.47 [95\% CI: 1.04, 2.06]), and 3.07 and 2.77 times the odds for meeting expectations in reading and writing respectively (Table 5: OR: 3.07, [95\% CI: 2.09, 4.51], OR: 2.77 [95\% CI: 1.83, 4.20]).

\section{Discussion}

We observed that meeting recommendations for diet, sleep and screen time had independent, positive effects for children's academic achievement. No association was found between meeting physical activity cutoffs and academic achievement. The findings from this study also indicated that the combined effects of meeting multiple lifestyle behavior recommendations had a stronger impact on academic achievement than the individual effects of lifestyle behaviors, particularly for reading and writing. We chose to evaluate lifestyle behaviors based 
Table 2 The associations between adherence to lifestyle behavior recommendations and meeting expectations on a standardized exam in Mathematics

\begin{tabular}{|c|c|c|c|c|c|c|}
\hline & \multicolumn{6}{|c|}{ Academic Achievement in Mathematics } \\
\hline & \multicolumn{2}{|l|}{ Univariable } & \multicolumn{2}{|l|}{ Model $1^{*}$} & \multicolumn{2}{|l|}{ Model $2^{* *}$} \\
\hline & $\mathrm{OR}(95 \% \mathrm{Cl})$ & $\overline{p \text {-value }}$ & $\mathrm{OR}(95 \% \mathrm{Cl})$ & $\overline{p \text {-value }}$ & OR $(95 \% \mathrm{Cl})$ & $p$-value \\
\hline \multicolumn{7}{|l|}{ Vegetables and Fruits } \\
\hline No (reference) & - & - & - & - & - & - \\
\hline Yes & $1.13(0.95,1.35)$ & 0.18 & $1.06(0.90,1.27)$ & 0.48 & $1.04(0.86,1.27)$ & 0.66 \\
\hline \multicolumn{7}{|l|}{ Grain Products } \\
\hline No (reference) & - & - & - & - & - & - \\
\hline Yes & $1.02(0.86,1.22)$ & 0.81 & $1.00(0.83,1.20)$ & 0.99 & $0.99(0.82,1.20)$ & 0.92 \\
\hline \multicolumn{7}{|l|}{ Milk and Alternatives } \\
\hline No (reference) & - & - & - & - & - & - \\
\hline Yes & $1.34(1.15,1.57)$ & $<0.001$ & $1.27(1.09,1.49)$ & 0.002 & $1.33(1.11,1.59)$ & 0.002 \\
\hline \multicolumn{7}{|l|}{ Meat and Alternatives } \\
\hline No (reference) & - & - & - & - & - & - \\
\hline Yes & $1.56(1.27,1.90)$ & $<0.001$ & $1.56(1.28,1.91)$ & $<0.001$ & $1.59(1.27,1.99)$ & $<0.001$ \\
\hline \multicolumn{7}{|l|}{ Saturated Fat } \\
\hline No (reference) & - & - & - & - & - & - \\
\hline Yes & $0.97(0.82,1.14)$ & 0.71 & $0.94(0.79,1.12)$ & 0.49 & $1.00(0.83,1.21)$ & 0.99 \\
\hline \multicolumn{7}{|l|}{ Free Sugars $<10 \%$ total kcal } \\
\hline No (reference) & - & - & - & - & - & - \\
\hline Yes & $1.63(1.38,1.93)$ & $<0.001$ & $1.33(1.12,1.57)$ & 0.001 & $1.20(0.99,1.45)$ & 0.06 \\
\hline \multicolumn{7}{|l|}{ PAQ-C } \\
\hline No (reference) & - & - & - & - & - & - \\
\hline Yes & $1.14(0.96,1.35)$ & 0.12 & $1.10(0.92,1.30)$ & 0.30 & $1.12(0.94,1.33)$ & 0.21 \\
\hline \multicolumn{7}{|l|}{ Sleep } \\
\hline No (reference) & - & - & - & - & - & - \\
\hline Yes & $1.44(1.01,2.02)$ & 0.04 & $1.26(0.88,1.80)$ & 0.20 & $1.42(0.97,2.07)$ & 0.71 \\
\hline \multicolumn{7}{|l|}{ Screen (TV) } \\
\hline No (reference) & - & - & - & - & - & - \\
\hline Yes & $1.33(1.11,1.60)$ & 0.002 & $1.11(0.92,1.35)$ & 0.28 & $1.02(0.83,1.25)$ & 0.86 \\
\hline \multicolumn{7}{|l|}{ Body Weight Status } \\
\hline Normal Weight (reference) & - & - & - & - & - & - \\
\hline Overweight or Obese & $0.95(0.79,1.13)$ & 0.533 & $1.00(0.84,1.20)$ & 0.97 & $0.98(0.82,1.17)$ & 0.81 \\
\hline \multicolumn{7}{|l|}{ Gender } \\
\hline Girl (reference) & - & - & - & - & - & - \\
\hline Boy & $1.09(0.93,1.28)$ & 0.27 & $1.08(0.92,1.27)$ & 0.22 & $1.11(0.94,1.30)$ & 0.22 \\
\hline \multicolumn{7}{|l|}{ Parental Education } \\
\hline Secondary or Less (ref) & - & - & - & - & - & - \\
\hline College Diploma & $1.50(1.20,1.86)$ & $<0.001$ & $1.32(1.07,1.63)$ & 0.01 & $1.32(1.06,1.65)$ & 0.01 \\
\hline University or Graduate Degree & $3.28(2.65,4.06)$ & $<0.001$ & $2.38(1.91,2.97)$ & $<0.001$ & $2.45(1.96,3.07)$ & $<0.001$ \\
\hline \multicolumn{7}{|l|}{ Household Income (CAN\$) } \\
\hline$<=20,000$ (reference) & - & - & - & - & - & - \\
\hline $20,001-40,000$ & $1.61(1.30,2.01)$ & $<0.001$ & $1.43(1.15,1.79)$ & 0.002 & $1.42(1.13,1.79)$ & 0.003 \\
\hline
\end{tabular}


Table 2 The associations between adherence to lifestyle behavior recommendations and meeting expectations on a standardized exam in Mathematics (Continued)

\begin{tabular}{|c|c|c|c|c|c|c|}
\hline $40,001-60,000$ & $2.03(1.63,2.53)$ & $<0.001$ & $1.49(1.21,1.85)$ & $<0.001$ & $1.44(1.15,1.80)$ & 0.001 \\
\hline$>=60,001$ & $3.43(2.71,4.35)$ & $<0.001$ & $2.05(1.58,2.65)$ & $<0.001$ & $2.03(1.56,2.63)$ & $<0.001$ \\
\hline \multicolumn{7}{|l|}{ Region of Residence } \\
\hline Rural (reference) & - & - & - & - & - & - \\
\hline Urban & $0.82(0.66,1.04)$ & 0.10 & $0.70(0.59,0.84)$ & $<0.001$ & $0.72(0.58,0.89)$ & 0.002 \\
\hline
\end{tabular}

*Model 1 adjusted for gender, parental education, household income, and region of residence. Results for Model 1 for confounders are the result of a model using only confounders as predictors

**Model 2 adjusted for above, weight status and all lifestyle behaviors

Results in bold are statistically significant $(p<0.05)$

on established recommendations that are widely accepted. Substantial efforts and resources go into the development and promotion of these recommendations, and findings from this study reveal that more efforts are needed to achieve compliance not only for the benefit of health, but for education.

The associations between dietary behaviors and academic achievement are supported by previous literature $[6,7,41-47]$. However, the majority of studies linking diet and academic achievement have tended to focus on breakfast consumption and whole diet, and few studies have evaluated the relationship between established dietary recommendations and academic achievement [7]. In particular, no study has evaluated the relationship between meeting newly released guidelines for free sugar recommendations, which exhibited a strong positive association with each of the three subjects. The lack of association between vegetables and fruit and academic achievement in this study seems inconsistent with much of the literature investigating the association between diet and academic achievement $[20,48]$. In previous studies, servings of vegetables and fruit have been assessed as a continuous variable, with more servings being positively associated with academic achievement. In this study, very few children met the recommendation for vegetables and fruit. As such, there may not have been sufficient power to detect any positive effect of meeting recommendations for vegetables and fruit. We conducted additional analyses treating servings of vegetables and fruit as a continuous variable, however, and no significant effect on academic achievement was observed. Milk and alternatives, meat and alternatives, and sugars consumption were more consistent predictors of higher academic achievement. This may be a reflection of a higher income household that is more likely to access and purchase products within these groups more regularly [49].

The observation that meeting designated cutoffs for physical activity levels associated with adequate cardiorespiratory fitness is not significantly associated with higher academic achievement complements existing findings in the literature investigating the relationship of physical activity with children's school performance. Much of the literature has concluded that the inclusion of more physical activity and physical education relative to other subjects in a school day does not negatively affect school performance [11, 13, 16, 50]. Many studies have found a relationship between children's physical activity levels and their academic achievement or cognitive development [11, 13, 51-53] though few studies have aimed to investigate its importance independent of other lifestyle behaviors. Another study found that the relationship between physical activity and academic achievement to be curvilinear, suggesting that children who are athletes may have many extra-curricular activities that displace time spent on academics [54]. Though cutoff values are useful in identifying sufficient levels of physical activity for physical health benefits, they may not be the most appropriate way to assess the association between physical activity and academic achievement as this relationship appears to be more complex. An analysis was conducted using PAQ-C score as a continuous variable (results not shown) and physical activity continued to have no effect on academic achievement. However, though the PAQ-C is a well-used and validated questionnaire, its intent is to provide a broad overview of children's moderate-to-vigorous physical activity levels and it does not provide detailed information about other intensities or frequency of physical activities or the physiological benefits children gain from regular physical activity that would contribute to their academic achievement, among other contributors. In addition, there was a time lag (1 year) between physical activity assessment and exam writing which may have introduced error. The PAQ-C measures regularly moderate-to-vigorous physical activity over a one week period which would not adequately capture the variability in the frequency of physical activity over a 1 year period. As such, this lack of association may be due to the limitations of the measure used, and further investigation using a more detailed means of measurement of children's physical activity is needed.

Sleep and screen time have been previously associated with academic achievement $[10,14,55]$. This is the second study, to our knowledge, to demonstrate the 
Table 3 The associations between adherence to lifestyle behavior recommendations and meeting expectations on a standardized exam in Reading

\begin{tabular}{|c|c|c|c|c|c|c|}
\hline & \multicolumn{6}{|c|}{ Academic Achievement in Reading } \\
\hline & \multicolumn{2}{|l|}{ Univariable } & \multicolumn{2}{|l|}{ Model $1^{*}$} & \multicolumn{2}{|l|}{ Model $2^{* *}$} \\
\hline & $\mathrm{OR}(95 \% \mathrm{Cl})$ & $\overline{p \text {-value }}$ & OR $(95 \% \mathrm{Cl})$ & $\overline{p \text {-value }}$ & OR $(95 \% \mathrm{Cl})$ & $\overline{p \text {-value }}$ \\
\hline \multicolumn{7}{|l|}{ Meets Vegetables and Fruits } \\
\hline No (reference) & - & - & - & - & - & - \\
\hline Yes & $1.44(1.13,1.83)$ & 0.003 & $1.30(1.02,1.66)$ & 0.03 & $1.19(0.91,1.56)$ & 0.20 \\
\hline \multicolumn{7}{|l|}{ Meets Grain Products } \\
\hline No (reference) & - & - & - & - & - & - \\
\hline Yes & $1.49(1.13,1.97)$ & 0.005 & $1.49(1.12,1.98)$ & 0.006 & $1.57(1.16,2.14)$ & 0.004 \\
\hline \multicolumn{7}{|l|}{ Meets Milk and Alternatives } \\
\hline No (reference) & - & - & - & - & - & - \\
\hline Yes & $1.25(1.02,1.53)$ & 0.03 & $1.24(1.00,1.53)$ & 0.045 & $1.46(1.16,1.84)$ & 0.001 \\
\hline \multicolumn{7}{|l|}{ Meets Meat and Alternatives } \\
\hline No (reference) & - & - & - & - & - & - \\
\hline Yes & $1.55(1.20,2.01)$ & 0.001 & $1.55(1.19,2.01)$ & 0.001 & $1.56(1.18,2.08)$ & 0.04 \\
\hline \multicolumn{7}{|l|}{ Meets Saturated Fat } \\
\hline No (reference) & - & - & - & - & - & - \\
\hline Yes & $1.36(1.13,1.65)$ & 0.001 & $1.28(1.06,1.56)$ & 0.01 & $1.28(1.01,1.62)$ & 0.04 \\
\hline \multicolumn{7}{|l|}{ Meets Free Sugars $<10 \%$ total kcal } \\
\hline No (reference) & - & - & - & - & - & - \\
\hline Yes & $1.91(1.57,2.32)$ & $<0.001$ & $1.56(1.28,1.90)$ & $<0.001$ & $1.29(1.02,1.62)$ & 0.03 \\
\hline \multicolumn{7}{|l|}{ Meets PAQ-C } \\
\hline No (reference) & - & - & - & - & - & - \\
\hline Yes & $1.14(0.90,1.45)$ & 0.28 & $1.05(0.82,1.34)$ & 0.70 & $1.05(0.82,1.36)$ & 0.66 \\
\hline \multicolumn{7}{|l|}{ Meets Sleep } \\
\hline No (reference) & - & - & - & - & - & - \\
\hline Yes & $1.33(0.89,2.00)$ & 0.16 & $1.21(0.79,1.88)$ & 0.38 & $1.39(0.90,2.13)$ & 0.14 \\
\hline \multicolumn{7}{|l|}{ Meets Screen Time } \\
\hline No (reference) & - & - & - & - & - & - \\
\hline Yes & $1.17(0.94,1.46)$ & 0.16 & $1.03(0.82,1.31)$ & 0.77 & $0.96(0.75,1.23)$ & 0.74 \\
\hline \multicolumn{7}{|l|}{ Body Weight Status } \\
\hline Normal Weight (reference) & - & - & - & - & - & - \\
\hline Overweight or Obese & $1.01(0.81,1.26)$ & 0.92 & $1.09(0.86,1.37)$ & 0.48 & $1.03(0.82,1.31)$ & 0.79 \\
\hline \multicolumn{7}{|l|}{ Gender } \\
\hline Girl (reference) & - & - & - & - & - & - \\
\hline Boy & $0.56(0.46,0.67)$ & $<0.001$ & $0.57(0.46,0.69)$ & $<0.001$ & $0.57(0.47,0.70)$ & $<0.001$ \\
\hline \multicolumn{7}{|l|}{ Parental Education } \\
\hline Secondary or Less (ref) & - & - & - & - & - & - \\
\hline College Diploma & $1.42(1.09,1.84)$ & 0.008 & $1.33(1.02,1.73)$ & 0.04 & $1.24(0.93,1.66)$ & 0.14 \\
\hline University or Graduate Degree & $2.56(1.92,3.41)$ & $<0.001$ & $1.89(1.40,2.55)$ & $<0.001$ & $1.89(1.37,2.60)$ & $<0.001$ \\
\hline \multicolumn{7}{|l|}{ Household Income (CAN\$) } \\
\hline$<=20,000$ (reference) & - & - & - & - & - & - \\
\hline $20,001-40,000$ & $1.31(0.97,1.77)$ & 0.78 & $1.20(0.90,1.62)$ & 0.22 & $1.23(0.89,1.70)$ & 0.21 \\
\hline
\end{tabular}


Table 3 The associations between adherence to lifestyle behavior recommendations and meeting expectations on a standardized exam in Reading (Continued)

\begin{tabular}{|c|c|c|c|c|c|c|}
\hline $40,001-60,000$ & $1.68(1.20,2.34)$ & 0.002 & $1.32(0.95,1.84)$ & 0.10 & $1.33(0.94,1.88)$ & 0.11 \\
\hline$>=60,001$ & $3.10(2.13,4.51)$ & $<0.001$ & $1.95(1.33,2.87)$ & 0.001 & $2.06(1.37,3.08)$ & $<0.001$ \\
\hline \multicolumn{7}{|l|}{ Region of Residence } \\
\hline Rural (reference) & - & - & - & - & - & - \\
\hline Urban & $1.23(0.96,1.57)$ & 0.11 & $1.03(0.84,1.25)$ & 0.81 & $1.11(0.87,1.41)$ & 0.41 \\
\hline
\end{tabular}

*Model 1 adjusted for gender, parental education, household income, and region of residence. Results for Model 1 for confounders are the result of a model using only confounders as predictors

**Model 2 adjusted for above, weight status and all lifestyle behaviors

Results in bold are statistically significant $(p<0.05)$

independent importance of meeting sleep recommendations for these behaviors for academic achievement [17]. In this study, sleep was found to only be associated with performance on writing exams. Sleep has been shown to be crucial for creativity and insight, key determinants of strong writing skills [56]. This study is also among the first to evaluate sleep duration and academic achievement using the National Sleep Foundation guideline [38]. Sleep is recommended within a range of hours, not as a minimum number of hours, and the finding that meeting these sleep recommendations is strongly associated with increased likelihood of meeting academic expectations in writing highlights the importance of both meeting the minimum requirements of sleep while not exceeding the maximum recommended number of hours $[38,57]$.

Few studies have investigated the association of body weight status and lifestyle behaviors simultaneously to determine their independent associations. Those that have, provide indication that it is not weight status that drives academic achievement, but that both academic achievement and body weight status are a result of longterm lifestyle behaviors $[17,18]$. This study complements this important work and indicates that promoting healthy lifestyles and values, rather than focusing on obesity prevention and reduction, is most effective in supporting optimal health, holistic wellness and academic achievement [23, 58-60].

Finally, the findings that the combined effects of lifestyle behaviors result in substantially higher likelihood of meeting expectations in all subjects is an important contribution to the literature. Ickovics et al. noted similar results in a sample of low-income American children of the same age - children with higher levels of 'health assets' including indicators of healthy diet, physical activity, screen time and sleep, were 2.2 times more likely to meet goals in mathematics, reading and writing compared to those who had the fewest health assets [25]. A Spanish study with the objective of investigating the combined effects of meeting recommendations for diet, physical activity, screen time and sleep on the self- reported grades of adolescents had similar findings for girls [17]. The present study complements and expands on these important findings drawing on a large, population-based sample of children. Collectively, these studies speak to the value of school-based health promotion initiatives that are more comprehensive in their approach compared to initiatives that address only singular aspects of health. Successful models of a comprehensive school health approach that have led to improvement in the healthfulness of children's lifestyle behaviors have been well-evaluated [31, 61]. Interventions that aim to improve multiple lifestyle behaviors may have a greater impact on academic achievement than those that focus on single behaviors.

Of note is girls' strong, positive association with the likelihood of meeting expectations for reading and writing. There was no gender effect for meeting expectations in mathematics. These results are consistent with other investigations about the school performance of girls and boys [62]. Stratified analyses by gender revealed no substantial differences between effects of individual lifestyle behaviors and academic achievement across gender (results not shown). Children's test scores are influenced by a multitude of factors, and differential influences between girls and boys, including self-confidence and parental support for specific career streams, are among them [62]. Further investigation is merited to determine the cause of the substantial gender differences in academic achievement in this population.

This study has several key strengths. First, it is a very large, population-based sample of children who are representative of an entire Canadian province. This study evaluated lifestyle behaviors with respect to established recommendations, which allows for easier interpretation and specific targets for health promotion initiatives. Non-response weighting was employed in order to account for non-response of students residing in lowerincome neighbourhoods in Nova Scotia. This study also used results from standardized exams from several different subjects, both eliminating bias from self-reported 
Table 4 The associations between adherence to lifestyle behavior recommendations and meeting expectations on a standardized exam in Writing

\begin{tabular}{|c|c|c|c|c|c|c|}
\hline & \multicolumn{6}{|c|}{ Academic Achievement in Writing } \\
\hline & \multicolumn{2}{|l|}{ Univariable } & \multicolumn{2}{|l|}{ Model $1^{*}$} & \multicolumn{2}{|l|}{ Model 2** } \\
\hline & $\mathrm{OR}(95 \% \mathrm{Cl})$ & $\overline{p \text {-value }}$ & $\mathrm{OR}(95 \% \mathrm{Cl})$ & $\overline{p \text {-value }}$ & OR $(95 \% \mathrm{Cl})$ & $p$-value \\
\hline \multicolumn{7}{|l|}{ Meets Vegetables and Fruits } \\
\hline No (reference) & - & - & - & - & - & - \\
\hline Yes & $1.35(1.06,1.71)$ & 0.02 & $1.20(0.93,1.54)$ & 0.16 & $1.08(0.81,1.43)$ & 0.61 \\
\hline \multicolumn{7}{|l|}{ Meets Grain Products } \\
\hline No (reference) & - & - & - & - & - & - \\
\hline Yes & $1.05(0.79,1.40)$ & 0.72 & $1.09(0.82,1.44)$ & 0.57 & $1.00(0.74,1.37)$ & 0.96 \\
\hline \multicolumn{7}{|l|}{ Meets Milk and Alternatives } \\
\hline No (reference) & - & - & - & - & - & - \\
\hline Yes & $1.15(0.91,1.45)$ & 0.25 & $1.08(0.85,1.37)$ & 0.54 & $1.10(0.85,1.43)$ & 0.46 \\
\hline \multicolumn{7}{|l|}{ Meets Meat and Alternatives } \\
\hline No (reference) & - & - & - & - & - & - \\
\hline Yes & $1.46(1.08,1.99)$ & 0.01 & $1.40(1.04,1.90)$ & 0.03 & $1.39(1.01,1.91)$ & 0.04 \\
\hline \multicolumn{7}{|l|}{ Meets Saturated Fat } \\
\hline No (reference) & - & - & - & - & - & - \\
\hline Yes & $1.23(0.99,1.52)$ & 0.06 & $1.18(0.95,1.48)$ & 0.141 & $1.16(0.90,1.49)$ & 0.25 \\
\hline \multicolumn{7}{|l|}{ Meets Free Sugars $<10 \%$ total kcal } \\
\hline No (reference) & - & - & - & - & - & - \\
\hline Yes & $1.66(1.35,2.04)$ & $<0.001$ & $1.43(1.16,1.77)$ & 0.001 & $1.41(1.13,1.49)$ & 0.002 \\
\hline \multicolumn{7}{|l|}{ Meets PAQ-C } \\
\hline No (reference) & - & & - & - & - & - \\
\hline Yes & $1.32(1.05,1.66)$ & 0.02 & $1.19(0.94,1.49)$ & 0.14 & $1.12(0.88,1.43)$ & 0.36 \\
\hline \multicolumn{7}{|l|}{ Meets Sleep } \\
\hline No (reference) & - & - & - & - & - & - \\
\hline Yes & $1.50(1.05,2.14)$ & 0.03 & $1.56(1.05,2.29)$ & 0.03 & $1.56(1.03,2.34)$ & 0.03 \\
\hline \multicolumn{7}{|l|}{ Meets Screen Time } \\
\hline No (reference) & - & - & - & - & - & - \\
\hline Yes & $1.47(1.16,1.88)$ & 0.002 & $1.43(1.12,1.83)$ & 0.004 & $1.35(1.04,1.75)$ & 0.03 \\
\hline \multicolumn{7}{|l|}{ Body Weight Status } \\
\hline Normal Weight (reference) & - & - & - & - & - & - \\
\hline Overweight or Obese & $0.80(0.63,1.03)$ & 0.08 & $0.84(0.65,1.08)$ & 0.17 & $0.82(0.64,1.06)$ & 0.14 \\
\hline \multicolumn{7}{|l|}{ Gender } \\
\hline Girl (reference) & - & - & - & - & - & - \\
\hline Boy & $0.44(0.36,0.55)$ & $<0.001$ & $0.42(0.34,0.52)$ & $<0.001$ & $0.45(0.36,0.56)$ & $<0.001$ \\
\hline \multicolumn{7}{|l|}{ Parental Education } \\
\hline Secondary or Less (ref) & - & - & - & - & - & - \\
\hline College Diploma & $1.20(0.89,1.63)$ & 0.24 & $1.33(1.07,1.65)$ & 0.01 & $1.16(0.84,1.61)$ & 0.36 \\
\hline University or Graduate Degree & $1.82(1.34,2.46)$ & $<0.001$ & $2.42(1.94,3.03)$ & $<0.001$ & $1.37(0.96,1.94)$ & 0.08 \\
\hline \multicolumn{7}{|l|}{ Household Income (CAN\$) } \\
\hline$<=20,000$ (reference) & - & - & - & - & - & - \\
\hline $20,001-40,000$ & $1.50(1.07,2.11)$ & 0.02 & $1.46(1.17,1.83)$ & 0.01 & $1.44(1.01,2.06)$ & 0.045 \\
\hline
\end{tabular}


Table 4 The associations between adherence to lifestyle behavior recommendations and meeting expectations on a standardized exam in Writing (Continued)

\begin{tabular}{|c|c|c|c|c|c|c|}
\hline $40,001-60,000$ & $1.65(1.18,2.30)$ & 0.003 & $1.53(1.23,1.90)$ & $<0.001$ & $1.51(1.03,2.21)$ & 0.04 \\
\hline$>=60,001$ & $2.66(1.80,3.93)$ & $<0.001$ & $2.42(1.94,3.03)$ & $<0.001$ & $2.10(1.31,3.36)$ & 0.002 \\
\hline \multicolumn{7}{|l|}{ Region of Residence } \\
\hline Rural (reference) & - & - & - & - & - & - \\
\hline Urban & $0.97(0.74,1.26)$ & 0.80 & $0.70(0.57,0.85)$ & $<0.001$ & $0.86(0.65 .1 .12)$ & 0.264 \\
\hline
\end{tabular}

grades and illustrating that lifestyle behaviors may have differential effects for different cognitive tasks. This study used validated questionnaires to assess diet and physical activity as well as directly measured heights and weights. Limitations of the study were the self-reported nature of lifestyle behaviors that can be prone to bias. The time lag between measurement of lifestyle behaviors and the writing of standardized exams may have introduced error to estimates of association. In the case of screen time, only TV watching was captured in this analysis and other forms of screen-based media which may be widely used were not included. In addition, questions used to assess sleep and screen time where not validated. As the CLASS study aims to collect a wide breadth of information, shorter, non-validated questions were used on surveys to reduce participant burden. Though a validated questionnaire was used to assess physical activity levels, the PAQ-C does not provided information about duration or intensity of physical activity, which is thought to be important in terms of its influence on academic achievement and relationship with meeting recommendations. As such, a lack of association may be due to the limited information provided by the tool used. Provided the large scope of this study, objective measurements of lifestyle behaviors were not feasible. Finally, standardized tests are only one means by which to evaluate children's academic success and their value has been disputed [63]. Investigations of the relationship between healthy lifestyle behaviors and other measures of academic success including enjoyment of school, psycho-social well-being, and sense of belonging are important complements to consider. There is also possibility of residual confounding by unmeasured variables including IQ and measures of mental health.

\section{Conclusions}

This study demonstrates that individual lifestyle behaviors have independent, positive associations with academic achievement, and that cumulative effects of multiple healthy lifestyle behaviors have a stronger positive association with academic outcomes in Reading and Writing than any individual association. These findings suggest that school-based health promotion approaches that address multiple lifestyle behaviors instead of single behaviors may have more benefit for academic achievement. Future studies investigating a longitudinal link between lifestyle behaviors, body weight and academic achievement are important to strengthen the prospective findings of this study and others similar to it.

Table 5 Mixed effects logistic regression models of the relationship between children's combined adherence to multiple lifestyle behavior recommendations and the odds of meeting expectations on standardized exams in Mathematics, Reading and Writing

\begin{tabular}{|c|c|c|c|c|c|c|}
\hline & \multicolumn{6}{|c|}{ Academic Achievement } \\
\hline & \multicolumn{2}{|l|}{ Mathematics } & \multicolumn{2}{|l|}{ Reading } & \multicolumn{2}{|l|}{ Writing } \\
\hline & $\mathrm{OR}(95 \% \mathrm{Cl})^{a}$ & $p$-value & $\mathrm{OR}(95 \% \mathrm{Cl})^{\mathrm{a}}$ & $\overline{p \text {-value }}$ & $\mathrm{OR}(95 \% \mathrm{Cl})^{\mathrm{a}}$ & $p$-value \\
\hline Per recommendation met ${ }^{\mathrm{b}}$ & $1.13(1.06,1.20)$ & $<0.001$ & $1.26(1.17,1.35)$ & $<0.001$ & $1.21(1.11,1.32)$ & $<0.001$ \\
\hline \multicolumn{7}{|c|}{ No. of Recommendations Met ${ }^{b}$} \\
\hline 3 or less & - & - & - & - & - & - \\
\hline $4-6$ & $1.12(0.81,1.54)$ & 0.50 & $1.85(1.32,2.59)$ & $<0.001$ & $1.98(1.38,2.84)$ & $<0.001$ \\
\hline $7-9$ & $1.47(1.04,2.06)$ & 0.03 & $3.07(2.09,4.51)$ & $<0.001$ & $2.77(1.83,4.20)$ & $<0.001$ \\
\hline
\end{tabular}

${ }^{a}$ Adjusted for body weight status, gender, parental education, parental income, region of residence and energy intake

${ }^{b}$ Includes meeting recommendations for vegetables and fruit, grain products, milk and alternatives, meat and alternatives, saturated fat, free sugars, physical activity cutoffs, sleep, and screen time

Results in bold are statistically significant $(p<0.05)$ 


\section{Additional file}

Additional file 1: Table S1. Correlations between Predictors of Interest: Meeting Recommendations for Lifestyle Behaviors among Grade 5 Students in Nova Scotia, Canada. (DOCX 69 kb)

\section{Abbreviations}

BMI: Body mass index; CLASS: Children's lifestyle and school-performance study; DQI: Diet quality index-international; IOTF: International obesity task force; PAQ-C: Physical activity questionnaire for children; YAQ: Harvard food frequency questionnaire for children and youth

\section{Acknowledgments}

Thank you to all participating grade 5 students and parents who contributed their information to the CLASS study. Thank you to all participating schools and teachers for allowing the CLASS team to conduct their study during school time. Thank you to the Nova Scotia Department of Early Education \& Early Childhood Development for allowing the educational data to be used for this research and specifically to Sarah Curry for her support in the data's use. Thank you to Dr. Stefan Kuhle for contributing to data management and for facilitating access to the data. Thank you to Dr. Sara Kirk for providing access to her workspace for data analysis. Thank you to Connie Lu for data management and to Xiuyun Wu for support with analysis.

\section{Funding}

The CLASS study was funded through an operating grant by the Canadian Institutes of Health Research [FRN: 93860]. The present work was supported by a Collaborative Research and Innovation Opportunities (CRIO) Team program from Alberta Innovates - Health Solutions (AIHS) [201300671]. ELF was supported by the Women and Children's Health Research Institute through the generous support of the Stollery Children's Hospital Foundation. MA is a MADD Canada Professor in Impaired Driving Research and Prevention. PJV holds a Canada Research Chair in Population Health, an Alberta Research Chair in Nutrition and Disease Prevention, and an Alberta Innovates Health Scholarship.

\section{Availability of data and materials}

The datasets are not publicly available due to ethical considerations. The authors will support access to the data where requests are reasonable and consistent with the ethical approval of the HREB at Dalhousie University and the University of Alberta.

\section{Authors' contributions}

PJV conceived and designed the study. PJV, ELF and JPE conceived and designed the analysis. ELF conducted the analysis and drafted the manuscript. PJV, JPE, DG, KES, and MA assisted in interpreting the data and critically revised the manuscript. All authors approve the final manuscript as submitted.

\section{Competing interests}

The authors declare that they have no competing interests.

\section{Consent for publication}

Not applicable. Consent for analysis of data and publication of results was provided by all parents and assent from children.

\section{Ethics approval and consent to participate}

The CLASS study received ethics approval from the Health Research Ethics Boards at the University of Alberta and Dalhousie University.

\section{Author details}

${ }^{1}$ Population Health Intervention Research Unit, School of Public Health, University of Alberta, 3-50 University Terrace, 8303-112 street, Edmonton, AB T6G 2T4, Canada. 'Department of Elementary Education, University of Alberta, 436 Education South Tower, 11210 - 87 ave, Edmonton, AB T6G 2G5, Canada. ${ }^{3}$ Department of Community Health and Epidemiology, Department of Emergency Medicine, Dalhousie University, Centre for Clinical Research, 4th Floor, 5790 University Avenue, Halifax, Nova Scotia B3H 1V7, Canada.
Received: 12 August 2016 Accepted: 3 February 2017

Published online: 09 March 2017

\section{References}

1. Mikkonen J, Raphael D. Social determinants of health: the Canadian facts. Toronto; 2010 Sep

2. Woolf SH. Potential health and economic consequences of misplaced priorities. JAMA. 2007;297:523-6.

3. Esteban-Cornejo I, Izquierdo-Gomez R, Gómez-Martínez S, Padilla-Moledo C, Castro-Piñero J, Marcos A, et al. Adherence to the Mediterranean diet and academic performance in youth: the UP\&DOWN study. Eur J Nutr. 2015;55:1133-40.

4. Matricciani L, Olds T, Petkov J. In search of lost sleep: secular trends in the sleep time of school-aged children and adolescents. Sleep Med Rev. 2012;16:203-11.

5. Carson V, Kuzik N, Hunter S, Wiebe SA, Spence JC, Friedman A, et al. Systematic review of sedentary behavior and cognitive development in early childhood. Prev Med. 2015;78:115-22.

6. Nyaradi A, Foster JK, Hickling S, Li J, Ambrosini GL, Jacques A, et al. Prospective associations between dietary patterns and cognitive performance during adolescence. J Child Psychol Psychiatry. 2014;55:1017-24.

7. Burrows T, Goldman S, Pursey K, Lim R. Is there an association between dietary intake and academic achievement: a systematic review. J Hum Nutr Diet. 2016. [Epub ahead of print]

8. Pindus DM, Davis RDM, Hillman CH, Bandelow S, Hogervorst E, Biddle SJH, et al. The relationship of moderate-to-vigorous physical activity to cognitive processing in adolescents: findings from the ALSPAC birth cohort. Psychol Res. 2015;79:715-28.

9. Hillman $\mathrm{CH}$. I. An introduction to the relation of physical activity to cognitive and brain health, and scholastic achievement. Monogr Soc Res Child Dev. 2014:79:1-6.

10. Schmidt RE, Van der Linden M. The relations between sleep, personality, behavioral problems, and school performance in adolescents. Sleep Med Clin. 2015:10:117-23.

11. Donnelly JE, Hillman CH, Castelli D, Etnier JL, Lee S, Tomporowski P, et al. Physical activity, fitness, cognitive function, and academic achievement in children: a systematic review. Med Sci Sports Exerc. 2016;48:1197-222.

12. Florence MD, Asbridge M, Veugelers PJ. Diet quality and academic performance. J School Health. 2008;78:209-15.

13. Singh A, Uijtdewilligen L, Twisk JWR, van Mechelen W, Chinapaw MJM. Physical activity and performance at school: a systematic review of the literature including a methodological quality assessment. Arch Pediatr Adolesc Med. 2012;166:49-55.

14. Hancox RJ, Milne BJ, Poulton R. Association of television viewing during childhood with poor educational achievement. Arch Pediatr Adolesc Med. 2005;159:614-8.

15. Stea TH, Torstveit MK. Association of lifestyle habits and academic achievement in Norwegian adolescents: a cross-sectional study. BMC Public Health. 2014:14:829.

16. Ahamed Y, Macdonald H, Reed K, Naylor P-J, Liu-Ambrose T, McKay H. School-based physical activity does not compromise children's academic performance. Med Sci Sports Exerc. 2007;39:371-6.

17. Martínez-Gómez D, Veiga OL, Gómez-Martínez S, Zapatera B, MartínezHernández D, Calle ME, et al. Gender-specific influence of health behaviors on academic performance in Spanish adolescents: the AFINOS study. Nutr Hosp. 2012;27:724-30.

18. Wang F, Veugelers PJ. Self-esteem and cognitive development in the era of the childhood obesity epidemic. Obes Rev. 2008;9:615-23.

19. Kristjánsson AL, Sigfúsdóttir ID, Allegrante JP. Health behavior and academic achievement among adolescents: the relative contribution of dietary habits, physical activity, body mass index, and self-esteem. Health Educ Behav. 2010;37:51-64.

20. Sigfúsdóttir ID, Kristjánsson AL, Allegrante JP. Health behaviour and academic achievement in Icelandic school children. Health Educ Res. 2006;22:70-80.

21. Taras H, Potts-Datema W. Sleep and student performance at school. J School Health. 2005;75:248-54.

22. Hale L, Guan S. Screen time and sleep among school-aged children and adolescents: a systematic literature review. Sleep Med Rev. 2015;21:50-8.

23. Kamath CC, Vickers KS, Ehrlich A, McGovern L, Johnson J, Singhal V, et al. Clinical review: behavioral interventions to prevent childhood obesity: a systematic review and metaanalyses of randomized trials. J Clin Endocrinol Metab. 2008:93:4606-15. 
24. Bradley BJ, Greene AC. Do health and education agencies in the United States share responsibility for academic achievement and health? A review of 25 years of evidence about the relationship of adolescents' academic achievement and health behaviors. J Adolesc Health. 2013;52:523-32.

25. Ickovics JR, Carroll-Scott A, Peters SM, Schwartz M, Gilstad-Hayden K, McCaslin C. Health and academic achievement: cumulative effects of health assets on standardized test scores among urban youth in the United States. J Sch Health. 2014;84:40-8.

26. Health Canada. Eating Well with Canada's Food Guide [Internet]. hc-sc.gc.ca. [cited 2014 Apr 11]. Available from: http://www.hc-sc.gc.ca/fn-an/foodguide-aliment/index-eng.php

27. World Health Organization. Guideline: sugars intake for adults and children. Geneva: World Health Organization; 2015.

28. United States Departments of Agriculture, Health, and Human Services. Dietary guidelines for Americans 2010 [Internet]. health.gov. 2010 [cited 2015 Jul 20]. Available from: http://www.health.gov/dietaryguidelines/ dga2010/DietaryGuidelines2010.pdf

29. Willett W. Nutritional epidemiology. 3rd ed. New York: Oxford University Press; 2013.

30. Rockett HR, Breitenbach M, Frazier AL, Witschi J, Wolf AM, Field AE, et al. Validation of a youth/adolescent food frequency questionnaire. Prev Med. 1997;26:808-16.

31. Fung C, Kuhle S, Lu C, Purcell M, Schwartz M, Storey K, et al. From "best practice" to "next practice": the effectiveness of school-based health promotion in improving healthy eating and physical activity and preventing childhood obesity. Int J Behav Nutr Phys Act. 2012;9:27.

32. Health Canada. Canadian nutrient file [Internet]. [cited 2014 Apr 11] Available from: https://food-nutrition.canada.ca/cnf-fce/index-eng.jsp.

33. Kowalski KC, Crocker PR. The physical activity questionnaire for older children (PAQ-C) and adolescents (PAQ-A) manual. College of Kinesiology; 2004

34. Crocker PR, Bailey DA, Faulkner RA, Kowalski KC, McGrath R. Measuring general levels of physical activity: preliminary evidence for the Physical Activity Questionnaire for Older Children. Med Sci Sports Exerc. 1997;29:1344-9.

35. Kowalski KC, Crocker PR, Faulkner RA. Validation of the Physical Activity Questionnaire for older children. Pediatr Exerc Sci. 1997;9:174-86.

36. Voss C, Ogunleye AA, Sandercock GRH. Physical Activity Questionnaire for children and adolescents: English norms and cut-off points. Pediatr Int. 2013;55:498-507.

37. Tremblay MS, LeBlanc AG, Janssen I. Canadian sedentary behaviour guidelines for children and youth. Appl Phys Nutr Metab. 2011;36:59-64.

38. National Sleep Foundation. Children and sleep [Internet]. sleepfoundation. org. [cited 2015 Aug 4]. Available from: http://sleepfoundation.org/sleeptopics/children-and-sleep

39. Cole TJ, Bellizzi MC, Flegal KM, Dietz WH. Establishing a standard definition for child overweight and obesity worldwide: international survey. BMJ. 2000; 320:1240-3.

40. Veugelers PJ, Fitzgerald AL. Effectiveness of school programs in preventing childhood obesity: a multilevel comparison. Am J Public Health. 2005;95:432-5.

41. Correa-Burrows $P$, Burrows $R$, Orellana $Y$, Ivanovic D. The relationship between unhealthy snacking at school and academic outcomes: a population study in Chilean schoolchildren. Public Health Nutr. 2015;18: 2022-30.

42. Lien L, Lien N, Heyerdahl S, Thoresen M, Bjertness E. Consumption of soft drinks and hyperactivity, mental distress, and conduct problems among adolescents in Oslo, Norway. Am J Public Health. 2006;96:1815-20.

43. Park S, Sherry B, Foti K, Blanck HM. Self-reported academic grades and other correlates of sugar-sweetened soda intake among US adolescents. J Acad Nutr Diet. 2012;112:125-31.

44. Vartanian LR, Schwartz MB, Brownell KD. Effects of soft drink consumption on nutrition and health: a systematic review and meta-analysis. Am J Public Health American Public Health Association. 2007;97:667-75.

45. Chung Y-C, Park C-H, Kwon H-K, Park Y-M, Kim YS, Doo J-K, et al. Improved cognitive performance following supplementation with a mixed-grain diet in high school students: a randomized controlled trial. Nutrition. 2012;28:165-72.

46. Willatts P. Long chain polyunsaturated fatty acids improve cognitive development. J Fam Health Care. 2002;12:5.

47. Taras H. Nutrition and student performance at school. J Sch Health. 2005;75: 199-213.

48. MacLellan D, Taylor J, Wood K. Food intake and academic performance among adolescents. Can J Diet Pract Res. 2008;69:141-4.
49. Kearney J. Food consumption trends and drivers. Philos Trans R Soc Lond B Biol Sci. 2010;365:2793-807.

50. Trudeau F, Shephard RJ. Physical education, school physical activity, school sports and academic performance. Int J Behav Nutr Phys Act. 2008:5:10.

51. Esteban-Cornejo I, Tejero-Gonzalez CM, Sallis JF, Veiga OL. Physical activity and cognition in adolescents: a systematic review. J Sci Med Sport. 2015;18:534-9.

52. Carson V, Hunter S, Kuzik N, Wiebe SA, Spence JC, Friedman A, et al. Systematic review of physical activity and cognitive development in early childhood. J Sci Med Sport. 2015;19:573-8.

53. Fedewa AL, Ahn S. The effects of physical activity and physical fitness on children's achievement and cognitive outcomes: a meta-analysis. Res Q Exerc Sport. 2011;82:521-35.

54. Syväoja HJ, Kantomaa MT, Ahonen T, Hakonen H, Kankaanpää A, Tammelin TH. Physical activity, sedentary behavior, and academic performance in Finnish children. Med Sci Sports Exerc. 2013:45:2098-104.

55. Gruber R, Wiebe ST, Wells SA, Cassoff J, Monson E. Sleep and academic success: mechanisms, empirical evidence, and interventional strategies. Adolesc Med State Art Rev. 2010;21:522-41-X.

56. Wagner U, Gais S, Haider H, Verleger R, Born J. Sleep inspires insight. Nature Nature Publishing Group. 2004;427:352-5.

57. Blunden S, Galland B. The complexities of defining optimal sleep: empirical and theoretical considerations with a special emphasis on children. Sleep Med Rev. 2014;18:371-8.

58. Hung L-S, Tidwell DK, Hall ME, Lee ML, Briley CA, Hunt BP. A meta-analysis of school-based obesity prevention programs demonstrates limited efficacy of decreasing childhood obesity. Nutr Res. 2015;35:229-40.

59. Sobol-Goldberg S, Rabinowitz J, Gross R. School-based obesity prevention programs: a meta-analysis of randomized controlled trials. Obesity (Silver Spring). 2013;21:2422-8.

60. Kretchmar RS. The increasing utility of elementary school physical education: A mixed blessing and unique challenge. The Elementary School Journal. 2008;108:161-70.

61. Luepker RV. Outcomes of a field trial to improve children's dietary patterns and physical activity. The Child and Adolescent Trial for Cardiovascular Health. CATCH collaborative group. JAMA. 1996;275:768-76.

62. OECD. What lies behind gender inequality in education? PISA in Focus, No. 49. Paris: OECD Publishing; 2015.

63. Canadian Education Association. The Facts on education: what is the value of standardized testing? http://www.cea-ace.ca/sites/cea-ace.ca/files/cea2014-foe-standardized-testing.pdf Accessed 2 Aug 2016.

\section{Submit your next manuscript to BioMed Central and we will help you at every step:}

- We accept pre-submission inquiries

- Our selector tool helps you to find the most relevant journal

- We provide round the clock customer support

- Convenient online submission

- Thorough peer review

- Inclusion in PubMed and all major indexing services

- Maximum visibility for your research

Submit your manuscript at www.biomedcentral.com/submit
Biomed Central 